\title{
Patient selection for whole brain radiotherapy (WBRT) in a large lung cancer cohort: Impact of a new Dutch guideline on brain metastases
}

Citation for published version (APA):

Hendriks, L. E. L., Troost, E. G. C., Steward, A., Bootsma, G. P., De Jaeger, K., van den Borne, B. E. E. M., \& Dingemans, A-M. C. (2014). Patient selection for whole brain radiotherapy (WBRT) in a large lung cancer cohort: Impact of a new Dutch guideline on brain metastases. Acta Oncologica, 53(7), 945-951. https://doi.org/10.3109/0284186X.2014.906746

Document status and date:

Published: 01/07/2014

DOI:

10.3109/0284186X.2014.906746

Document Version:

Publisher's PDF, also known as Version of record

Document license:

Taverne

Please check the document version of this publication:

- A submitted manuscript is the version of the article upon submission and before peer-review. There can be important differences between the submitted version and the official published version of record.

People interested in the research are advised to contact the author for the final version of the publication, or visit the DOI to the publisher's website.

- The final author version and the galley proof are versions of the publication after peer review.

- The final published version features the final layout of the paper including the volume, issue and page numbers.

Link to publication

\footnotetext{
General rights rights.

- You may freely distribute the URL identifying the publication in the public portal. please follow below link for the End User Agreement:

www.umlib.nl/taverne-license

Take down policy

If you believe that this document breaches copyright please contact us at:

repository@maastrichtuniversity.nl

providing details and we will investigate your claim.
}

Copyright and moral rights for the publications made accessible in the public portal are retained by the authors and/or other copyright owners and it is a condition of accessing publications that users recognise and abide by the legal requirements associated with these

- Users may download and print one copy of any publication from the public portal for the purpose of private study or research.

- You may not further distribute the material or use it for any profit-making activity or commercial gain

If the publication is distributed under the terms of Article 25fa of the Dutch Copyright Act, indicated by the "Taverne" license above, 


\section{Patient selection for whole brain radiotherapy (WBRT) in a large lung cancer cohort: Impact of a new Dutch guideline on brain metastases}

Lizza E. L. Hendriks, Esther G. C. Troost, Allan Steward, Gerben P. Bootsma, Katrien De Jaeger, Ben E. E. M. van den Borne \& Anne-Marie C. Dingemans

To cite this article: Lizza E. L. Hendriks, Esther G. C. Troost, Allan Steward, Gerben P. Bootsma, Katrien De Jaeger, Ben E. E. M. van den Borne \& Anne-Marie C. Dingemans (2014) Patient selection for whole brain radiotherapy (WBRT) in a large lung cancer cohort: Impact of a new Dutch guideline on brain metastases, Acta Oncologica, 53:7, 945-951, DOI: 10.3109/0284186X.2014.906746

To link to this article: https://doi.org/10.3109/0284186X.2014.906746

Published online: 23 Apr 2014.

Џlll Article views: 931

View Crossmark data ¿
Submit your article to this journal $\asymp$

Q View related articles ¿

Citing articles: 4 View citing articles 주 


\title{
Patient selection for whole brain radiotherapy (WBRT) in a large lung cancer cohort: Impact of a new Dutch guideline on brain metastases
}

\author{
LIZZA E. L. HENDRIKS ${ }^{1}$, ESTHER G. C. TROOST ${ }^{2}$, ALLAN STEWARD ${ }^{1}$, \\ GERBEN P. BOOTSMA ${ }^{3}$, KATRIEN DE JAEGER ${ }^{4}$, BEN E. E. M. VAN DEN BORNE ${ }^{5} \&$ \\ ANNE-MARIE C. DINGEMANS ${ }^{1}$ \\ ${ }^{1}$ Department of Pulmonary Diseases, GROW - School for Oncology and Developmental Biology, Maastricht \\ University Medical Center, Maastricht, The Netherlands, ${ }^{2}$ Department of Radiation Oncology (Maastro Clinic), \\ GROW - School for Oncology and Developmental Biology, Maastricht University Medical Center, Maastricht, The \\ Netherlands, ${ }^{3}$ Department of Pulmonary Diseases, Atrium Medical Center, Heerlen, The Netherlands, ${ }^{4}$ Department of \\ Radiotherapy, Catharina Hospital, Eindhoven, The Netherlands and ${ }^{5}$ Department of Pulmonary Diseases, Catharina \\ Hospital, Eindhoven, The Netherlands
}

\section{ABSTRACT}

Background. Median survival after diagnosis of brain metastases is, depending on the Recursive Partitioning Analysis (RPA) classes, 7.1 (class I) to 2.3 months (class III). In 2011 the Dutch guideline on brain metastases was revised, advising to withhold whole brain radiotherapy (WBRT) in RPA class III. In this large retrospective study, we evaluated the guideline's use in daily practice.

Material and methods. Data of 428 lung cancer patients undergoing WBRT for brain metastases (2004-2012) referred from three Dutch hospitals were retrospectively analyzed. Details on Karnofsky performance score (KPS), age, control of primary tumor, extracranial metastases, histology, and survival after diagnosis of brain metastases were collected. RPA class was determined using the first four items.

Results. In total 327 patients had non-small cell lung cancer (NSCLC) and 101 small cell lung cancer (SCLC). For NSCLC, $6.1 \%, 71.9 \%$, and $16.2 \%$ were classified as RPA I, II, and III, respectively, and $5.8 \%$ could not be classified. For SCLC this was 8.9\%, 66.3\%, 14.9\%, and 9.9\%, respectively. Before the revised guideline was implemented, $11.3-21.3 \%$ of WBRT patients were annually classified as RPA III. In the year thereafter, this was $13.0 \%(\mathrm{p}=0.646)$. Median survival (95\% CI) for NSCLC RPA class I, II, and III was 11.4 (9.9-12.9), 4.0 (3.4-4.7), and 1.7 (1.3-2.0) months, respectively. For SCLC this was 7.9 (4.1-11.7), 4.7 (3.3-6.1), and 1.7 (1.5-1.8) months.

Conclusions. Although it is advised to withhold WBRT in RPA class III patients, in daily practice $11.3-21.3 \%$ of WBRT-treated patients were classified as RPA III. The new guideline did not result in a decrease. Reasons for referral of RPA III patients despite a low KPS were not found. Despite WBRT, survival of RPA III patients remains poor and this poor outcome should be stressed in practice guidelines. Therefore, better awareness amongst physicians would prevent some patients from being treated unnecessarily.

More than $50 \%$ of all intracranial tumors are metastases from extracranial primary tumor sites [1]. Of these primary tumors, lung cancer is the most frequent [2] and $30-60 \%$ of lung cancer patients will develop brain metastases [3,4]. The Radiation Therapy Oncology Group (RTOG) has identified pretreatment variables that determine survival after the diagnosis of brain metastases including age, Karnofsky performance status (KPS), control of primary tumor, absence of extracranial metastases and primary tumor site (e.g. breast cancer vs. lung cancer) [5]. Based on the Recursive Partitioning

Correspondence: L. E. L. Hendriks, Department of Pulmonary Diseases, Maastricht University Medical Center, PO Box 5800 , 6202 AZ Maastricht, The Netherlands. Tel: + 31 433871318. Fax: + 31 433875051. E-mail: lizza.hendriks@mumc.nl 
Analysis (RPA) classification using the above mentioned variables (except for primary tumor site) patients can be divided into three categories: class I with good prognosis, class II with intermediate and class III with poor prognosis (see Table I) [5]. RPA classification has been validated in both non-small cell lung cancer (NSCLC) and small cell lung cancer (SCLC). Survival ranges from a median of 7.1 months for RPA class I to 2.3 months for RPA class III [5-7]. Whole Brain Radiotherapy (WBRT) is considered the standard treatment for patients with brain metastases not eligible for (radio)surgery or stereotactic radiotherapy [8]. Potential benefits of WBRT are improved quality of life and performance status, improved neurological function, and a reduction in steroid dose needed to control neurological symptoms. However, the benefit of WBRT as compared to best supportive care (BSC) alone has not been studied in randomized controlled trials [9].

Moreover, data of an unplanned interim analysis (due to poor accrual) of the phase III QUARTZ trial (NCT00403065) comparing BSC with BSC plus WBRT in inoperable brain metastases from NSCLC indicate that, with BSC only, there is no evidence of worsening quality of life or overall survival in patients for whom clinician and patient are uncertain of the benefit of WBRT [10].

Current practice is that most guidelines (European Society of Medical Oncology, National Institute for Health and Clinical Excellence, National Comprehensive Cancer Network) advise WBRT combined with BSC without taking into account the RPA classification or another prognostic classification [1113]. However, in the revised Dutch guideline 'brain metastases from solid tumors' (version 3.0, July 2011) it is advised to treat patients with more than three metastatic lesions in RPA class I and the majority of the patients in RPA class II actively with WBRT and to treat patients in RPA class III primarily

Table I. RPA class and survival (current study and RTOG analysis).

\begin{tabular}{|c|c|c|c|c|}
\hline \multirow{2}{*}{$\begin{array}{l}\text { RPA } \\
\text { class }\end{array}$} & \multirow[b]{2}{*}{ Description } & \multicolumn{2}{|c|}{$\begin{array}{l}\text { Current study } \\
\text { Median survival } \\
\text { (months) }\end{array}$} & \multirow{2}{*}{$\begin{array}{l}\text { RTOG analysis } \\
\text { [5] Median } \\
\text { survival } \\
\text { (months) }\end{array}$} \\
\hline & & NSCLC & SCLC & \\
\hline I & $\begin{array}{l}\text { KPS } \geq 70 \text { AND } \\
\text { Age }<65 \text { years } \\
\text { AND Controlled } \\
\text { systemic disease } \\
\text { AND Metastases } \\
\text { to brain only }\end{array}$ & 11.4 & 7.9 & 7.1 \\
\hline II & all other patients & 4.0 & 4.7 & 4.2 \\
\hline III & $\mathrm{KPS}<70$ & 1.7 & 1.7 & 2.3 \\
\hline
\end{tabular}

KPS, Karnofsky Performance Score; RPA, Recursive Partitioning Analysis. symptomatically with BSC [14]. The performance score is often implemented in decision making in other guidelines but RPA classification, although validated, is not implemented in these guidelines. As RPA class seems strong in predicting early death [15], its use was advised in the revised Dutch guideline.

The aim of this study was to analyze whether the revised Dutch national guideline had impact on the selection of patients for WBRT, i.e. whether the percentage of RPA III patients who underwent WBRT decreased. Results for referral of RPA III patients despite a low performance score were also studied. Furthermore, the survival data of the studied patient cohort were compared to the survival reported in the RTOG validation studies [5].

\section{Material and methods}

\section{Patient selection}

Data of 428 lung cancer patients from three teaching hospitals in the South of the Netherlands who underwent WBRT for brain metastases between March 2004 and July 2012 were retrospectively analyzed. WBRT was delivered at MAASTRO Clinic (Maastricht) and the Catharina Hospital (Eindhoven). Details on age, gender, performance score (according to WHO/KPS), histology, local (intrathoracic) disease control, presence of extracranial metastases, time from diagnosis of lung cancer to development of brain metastases, and date of death or last follow-up visit were collected. Control of the primary tumor was defined as a complete tumor response or lack of local progression for at least three months before WBRT [based on chest x-ray or computed tomography (CT) of the chest]. Diagnosis of extracranial metastases was based on CTs of the chest and upperabdomen, bone scintigraphy or ultrasound of the abdomen within one month of diagnosis of brain metastases. When only a chest $\mathrm{x}$-ray was performed, the presence of extracranial metastases was stated as unknown. Brain metastases were defined as synchronous if discovered at the time of diagnosis of the primary cancer or within two months thereafter [2]. The RPA class was determined using the following four items: KPS, age, local disease control and presence of extracranial metastases. Histology was divided into NSCLC and SCLC, whereby NSCLC was further subgrouped in squamous cell carcinoma, adenocarcinoma, large cell carcinoma and "not otherwise specified" (NOS). Survival time was assessed from the date of diagnosis of brain metastases on imaging till death. Last date of follow-up was February 2013. The study was approved by the local science committee and was conducted according to the Code of Conduct for the use of data in Health Research and the Dutch "use of patient data" law. 


\section{Statistical methods}

All analyses were performed using SPSS statistical software (SPSS for Windows, version 20.0, IBM). Overall survival from time of diagnosis of brain metastases until death was calculated for all included NSCLC and SCLC patients per RPA class using the Kaplan-Meier method. A log rank test was performed to compare survival times between RPA classes. Pearson's $\chi^{2}$-test was used to evaluate whether there was a difference in RPA class III before and after implementation of the revised guideline.

\section{Results}

\section{Patient characteristics}

Between 2004 and 2012, a total of 327 NSCLC and 101 SCLC patients underwent WBRT at two radiotherapy departments. All patients received WBRT delivered with a $6 \mathrm{MV}$ linear accelerator using two lateral fields. The prescribed dose was $5 \times 4$ Gy. In the NSCLC patient group, the mean age (range) was 62.2 years (40.4-85.2), $55.4 \%$ was male and 266 patients $(81.3 \%)$ had a KPS of at least 70 . In 208 patients $(63.6 \%)$ the primary tumor was uncontrolled, $139(42.5 \%)$ had extracranial metastases and $157(48.0 \%)$ had brain metastases at primary diagnosis (Table II).

In the SCLC patient group, the mean age was 64.0 years (44.7-85.7), $58.2 \%$ was male and 81
$(80.2 \%)$ had a KPS of at least 70 . In 60 patients $(59.4 \%)$ the primary tumor was not controlled, 43 patients $(42.6 \%)$ had extracranial metastases and 41 patients $(40.6 \%)$ had brain metastases at primary diagnosis (Table II).

\section{RPA classification}

For NSCLC, 20 of 327 patients $(6.1 \%)$ were classified as RPA I, 235 patients (71.9\%) as RPA II, and $53(16.2 \%)$ as RPA III. RPA could not be defined in 19 patients $(5.8 \%)$.

For SCLC the corresponding numbers were 9 $(8.9 \%), 67(66.3 \%), 15(14.9 \%)$, and $10(9.9 \%)$, respectively.

\section{Survival}

The majority of patients were dead at the time of analysis. Nine NSCLC patients $(2.8 \%)$ and two SCLC patients $(2.0 \%)$ were alive. For one NSCLC patient the date of death was unknown. These patients were classified as censored observations at the time of last follow-up. Eight NSCLC (five RPA II, three RPA III) and two SCLC (one RPA II, one RPA III) patients did not start or complete radiotherapy due to progressively deteriorating KPS. Since these patients were first considered eligible for WBRT, they were included in the analysis with the intention to treat principle.

\begin{tabular}{|c|c|c|}
\hline Patient characteristics & $\begin{array}{l}\text { NSCLC } \\
\mathrm{N}=327\end{array}$ & $\begin{array}{c}\text { SCLC } \\
\mathrm{N}=101\end{array}$ \\
\hline Mean age (range) & $62.2(40.4-85.2)$ & $62.1(44.7-83.5)$ \\
\hline$\%$ male & 55.4 & 64.0 \\
\hline \multicolumn{3}{|l|}{ Histology } \\
\hline Adenocarcinoma & $145(44.3 \%)$ & \\
\hline Squamous cell carcinoma & $37(11.3 \%)$ & \\
\hline Large cell carcinoma & $60(18.3 \%)$ & \\
\hline Not otherwise specified & $85(26.1 \%)$ & \\
\hline \multicolumn{3}{|l|}{ Performance (KPS) } \\
\hline$\geq 70$ & $266(81.3 \%)$ & $81(80.1 \%)$ \\
\hline$<70$ & $53(16.2 \%)$ & $15(14.9 \%)$ \\
\hline Missing & $8(2.5 \%)$ & $5(5.0 \%)$ \\
\hline \multicolumn{3}{|c|}{ Diagnosis of primary to development of BM } \\
\hline Synchronous & $157(48.0 \%)$ & $41(40.6 \%)$ \\
\hline Metachronous & $170(52.0 \%)$ & $60(59.4 \%)$ \\
\hline \multicolumn{3}{|l|}{ KPS $\geq 70$, control of primary } \\
\hline Under control & $41(15.4 \%)$ & $17(21.0 \%)$ \\
\hline Uncontrolled & $208(78.2 \%)$ & $60(74.1 \%)$ \\
\hline Unknown & $17(6.4 \%)$ & $4(4.9 \%)$ \\
\hline \multicolumn{3}{|c|}{$\mathrm{KPS} \geq 70$, extracranial Metastases } \\
\hline No & $104(39.1 \%)$ & $32(39.5 \%)$ \\
\hline Yes & $146(54.8 \%)$ & $44(54.3 \%)$ \\
\hline Unknown & $16(6.1 \%)$ & $5(6.2 \%)$ \\
\hline
\end{tabular}

BM, brain metastases; KPS, Karnofsky Performance Score; NSCLC, non-small cell lung cancer; SCLC, small cell lung cancer. 
Median survival (95\% CI) for NSCLC RPA class I, II, and III was 11.4 (9.9-12.9), 4.0 (3.4-4.7), and 1.7 (1.3-2.0) months, respectively. This difference was statistically significant $(\mathrm{p}<0.0001)$ (Figure $1 \mathrm{~A})$. For the NSCLC patients with an unknown RPA classification, median survival was 2.7 (2.4-3.0) months.

For SCLC median survival (95\% CI) for RPA class I, II, and III was statistically significant different at $7.9(4.1-11.7), 4.7(3.3-6.1)$, and $1.7(1.5-1.8)$ months, respectively $(p<0.0001)$ (Figure $1 B)$. For the SCLC patients with an unknown RPA class median survival was 4.2 (3.5-5.0) months.

In the large group of RPA class II patients a subgroup analysis was performed to evaluate whether there were patient groups with different survival. Patients with extracranial metastases had a significantly worse median survival compared to patients without [3.7 (2.8-4.5) vs. 5.7 (4.7-6.7) months $(p=0.004)$ ] Figure 1C. Age under or over 65 years had no impact, median survival was respectively 4.6 (3.9-5.2) and $3.5(2.8-4.1)$ months $(\mathrm{p}=0.472)$. The same was found for control or no control of primary tumor, median survival was respectively 3.5 (1.65.4) and $4.3(3.6-4.9)$ months $(\mathrm{p}=0.912)$.

\section{RPA class III patients}

In order to evaluate why RPA class III patients were treated despite a low KPS, a more detailed analysis was performed.

RPA class III patients were divided according to the presence or absence of extracranial metastases and to the presence of synchronous or metachronous brain metastases. Regarding the first, it was hypothesized
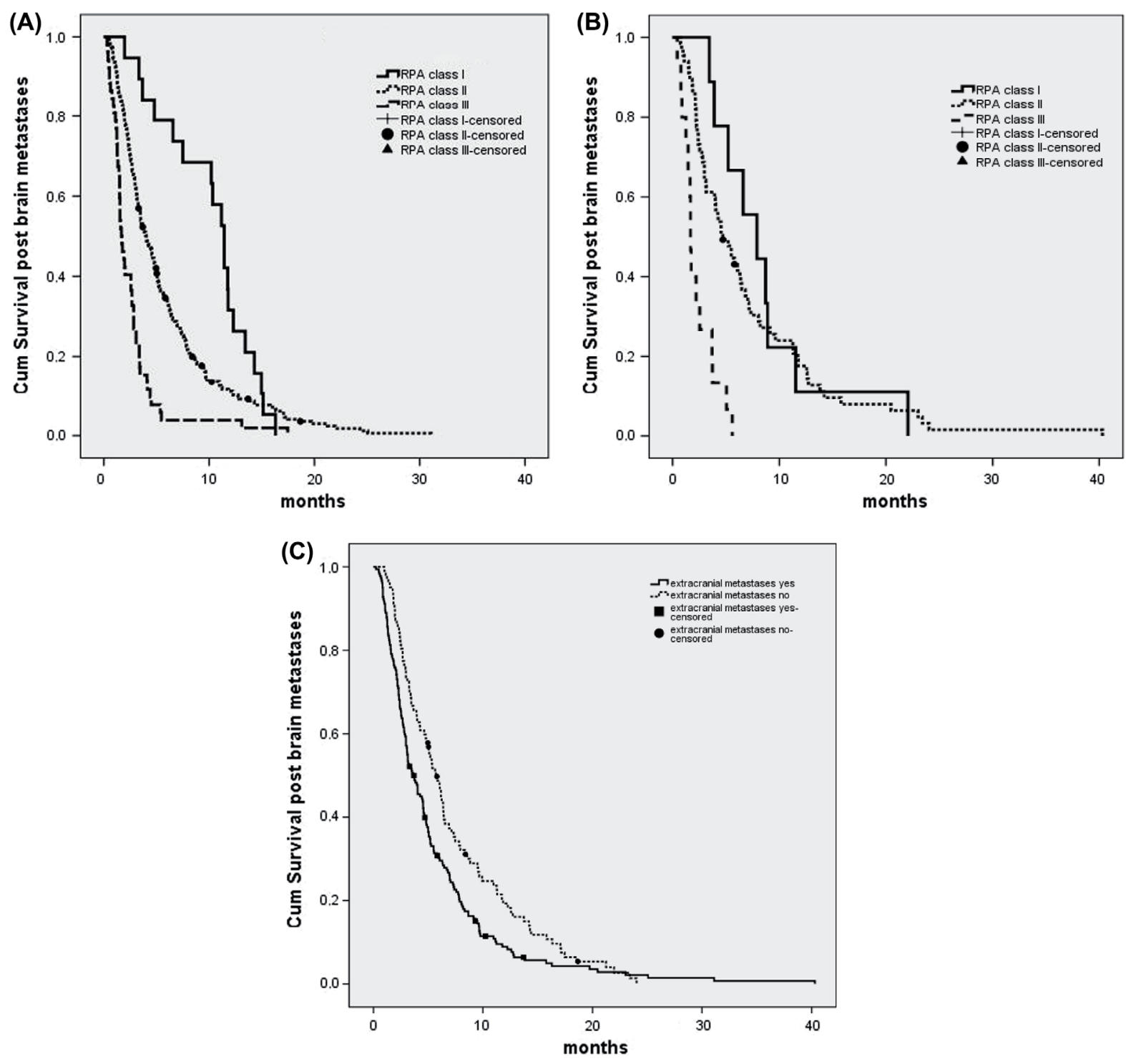

Figure 1. (A) Survival post brain metastases in NSCLC patients per RPA class. (B) Survival post brain metastases in SCLC patients per RPA class. (C) Survival in RPA class II subgroups with and without extracranial metastases. 
that RPA class III patients with solely brain metastases and no extracranial metastases at diagnosis were treated with WBRT despite a low KPS.

Regarding the latter, it was postulated that having a first line systemic treatment option available could also be a reason to treat these patients (although palliative systemic treatment is not recommended in patients with a low KPS, with a possible exception of SCLC patients because of high response rates to first line chemotherapy).

However, the majority $(60.0 \%$ of NSCLC and $67.3 \%$ of SCLC) of RPA III patients was diagnosed with extracranial metastases, and $50.0 \%$ of NSCLC and $66.6 \%$ of SCLC patients had metachronous brain metastases. With the exception of SCLC patients diagnosed with synchronous brain metastases [only three patients, median survival 5.0 (0.010.3) months], median survival for NSCLC and SCLC was $1.2-2.8$ months (Table III).

Due to the low number of patients, groups were not further subdivided into controlled versus uncontrolled primary tumor.

\section{Effect of the revised guideline}

Before the revised Dutch national guideline was implemented in 2011, 11.3-21.3\% of WBRT patients was annually classified as RPA III (on average nine patients per year). In the year after implementing the guideline, this number only slightly dropped to $13.0 \%$ (six patients per year) $(p=0.646)$.

\section{Discussion}

Brain metastasis frequently occurs in lung cancer patients and is related with a poor outcome $[3,4]$.
Despite the recommendations in the Dutch national guideline, in our cohort $16.2 \%$ of NSCLC and $14.9 \%$ of SCLC patients treated with WBRT were RPA class III. Despite the release/implementation of the new national guideline in 2011 , no substantial decrease in class III patients as percentage of the total of patients treated with WBRT was observed.

It is still largely unknown whether a poor overall prognosis is not only a poor prognostic factor for survival, but also a predictive factor for the poor effects of WBRT. In older studies (in which all patients were treated with WBRT) a poor performance score was found to be a poor prognostic factor. In two recent studies (one interim-analysis only), this appeared to be also a poor predictive factor as there was no difference in survival between patients treated with and without WBRT $[10,16]$.

Our study confirms the dismal outcome of these RPA III patients. A possible explanation for (continuing) treating RPA class III patients is that physicians overestimate the benefit of WBRT [17]. Furthermore, cancer patients and their relatives may have unrealistic expectations and are more often than non-cancer patients willing to accept an aggressive potentially toxic treatment with little or no benefit on survival or quality of life [18].

In our study no explanation was found for treating RPA class III patients despite their poor performance score. Most of these patients were already treated with first line chemotherapy and were not diagnosed with brain metastases as the only site of disease activity (i.e. they did not have a more favorable prognosis).

Potential benefits of WBRT are not well studied and there are no completed randomized trials of

Table III. RPA class III characteristics and survival.

\begin{tabular}{|c|c|c|c|c|}
\hline RPA class III [N (\%)] & $\begin{array}{l}\text { Synchronous } \\
\text { BM }[N(\%)]\end{array}$ & $\begin{array}{l}\text { Median survival } \\
\text { (95\% CI) } \\
\text { months }\end{array}$ & $\begin{array}{l}\text { Metachronous } \\
\text { BM [N (\%)] }\end{array}$ & $\begin{array}{l}\text { Median } \\
\text { survival, } \\
\text { months }\end{array}$ \\
\hline \multicolumn{5}{|l|}{$\operatorname{NSCLC}(\mathrm{N}=52)$} \\
\hline $\begin{array}{l}\text { With ECM } \\
\text { N (\%) } 35 \text { (67.3) } \\
\text { Without ECM }\end{array}$ & $14(40.0)$ & $1.7(1.5-1.9)$ & $21(60.0)$ & $1.5(1.2-1.8)$ \\
\hline $\begin{array}{l}\mathrm{N}(\%) 11(21.2) \\
\text { Unknown ECM }\end{array}$ & $6(54.5)$ & $2.0(0.1-3.8)$ & $5(45.5)$ & $2.8(0.0-7.7)$ \\
\hline N (\%) 6 (11.5) & $3(50.0)$ & $1.7(1.0-2.6)$ & $3(50.0)$ & $1.5(0.9-2.1)$ \\
\hline $\begin{array}{c}\text { SCLC }(\mathrm{N}=15) \\
\text { With ECM }\end{array}$ & & & & \\
\hline $\begin{array}{l}\text { N (\%) } 9(60.0) \\
\text { Without ECM }\end{array}$ & $3(33.3)$ & $5.0(0.0-10.3)$ & $6(66.6)$ & $1.7(0.1-3.3)$ \\
\hline $\begin{array}{l}\mathrm{N}(\%) 3(20.0) \\
\text { Unknown ECM }\end{array}$ & $1(33.3)$ & $1.4(\mathrm{~N} / \mathrm{A})$ & $2(66.6)$ & $1.6(\mathrm{~N} / \mathrm{A})$ \\
\hline $\mathrm{N}(\%) 3(20.0)$ & $0(0.0)$ & N/A & $3(100)$ & $1.2(0.5-2.0)$ \\
\hline
\end{tabular}

BM, brain metastases; ECM, extracranial metastases; NSCLC, non-small cell lung cancer; RPA, Recursive Partitioning Analysis; SCLC, small cell lung cancer. 
WBRT versus BSC with adequately defined endpoints. In older WBRT studies [19] symptomatic responses following WBRT of more than $60 \%$ were noted, but quality of life was not the primary endpoint. Also, response was not well defined, without any separation between response to corticosteroids or WBRT, and with measurement techniques that were neither standardized nor validated. More recent studies and a Cochrane review suggest that there is either only a modest effect of WBRT on quality of life and/or survival, or that no conclusion can be drawn [20-23]. Moreover, there is evidence that in NSCLC patients for whom the clinician (i.e. multidisciplinary lung/neuro-oncology team) and/or patient are uncertain of the benefit of WBRT, withholding WBRT does not harm the patient. An unplanned interim analysis of the QUARTZ trial $(\mathrm{N}=151)$ indicated that there is no early evidence of worsening quality-adjusted life years (primary endpoint) for these NSCLC patients when treated with BSC only [10]. The total accrual of 534 patients in this study with a highly relevant primary endpoint for these patients is expected mid-2014. A recent retrospective study $(\mathrm{N}=113)$ in patients with brain metastases and adverse prognostic factors reported comparable results [16]. Another recent prospective non-randomized study $(\mathrm{N}=91)$ found no additive value of WBRT to optimal supportive care in RPA class III patients (predominantly NSCLC) [23].

However, current practice is that most guidelines advise WBRT in addition to optimal supportive care [11-13]. Although the performance score is used for decision making in other guidelines, RPA classification is not mentioned. Furthermore, according to our study, presence or absence of extracranial metastases could be used in RPA class II to further refine the prognostic classification in this group. In the original RTOG analysis, this retained no significance, but it is possible that for lung cancer patients the presence of extracranial metastases is also a poor prognostic factor.

There are some drawbacks to this study. First of all, due to the retrospective design we were unable to collect all data (e.g. on performance status, control of primary tumor or extracranial metastases). In clinical routine, the evaluation of the extent of the intrathoracic disease is somewhat arbitrary and the effort to evaluate the extent of extrathoracic disease is typically modest once the diagnosis of brain metastases is established. Despite this, evaluation of extracranial disease is important because of the prognostic implications as we have shown in the subgroup of RPA class II patients. Due to these missing data we were unable to determine the RPA class for all patients (5.8\% of NSCLC patients and $9.9 \%$ of SCLC patients). Second, the retrospective nature led to a slightly different distribution of patients in the RPA classes compared to the original RTOG analysis [5]. In our study, less patients were classified as RPA class I and more as RPA class II. In the only study validating RPA classification for SCLC-only patients with brain metastases, more patients were classified as RPA III (33\% compared to $14.9 \%$ in our series) [7].

Except for NSCLC RPA class I, survival data were comparable to the original RTOG analysis (Table I) [5] as well as to three lung cancer only studies $[6,7,24]$. It is possible that due to the small sample size our NSCLC RPA class I cohort is a highly selected group with a favorable histology and thus longer survival. Third, we did not have full data regarding patients who were evaluated by the radiation oncologist but were considered ineligible for WBRT. For those evaluated, low performance score was the main reason for ineligibility. Data regarding patients who were never considered candidates for WBRT by the treating pulmonologist or multidisciplinary team were not retrievable. It would be interesting to investigate why some RPA class III patients are considered candidates for WBRT and some are not.

Fourth, only two radiotherapy departments (easily accessed by the three referral hospitals) were included in our analysis. This may not be representative for the whole country, however, the lack of use of RPA class in other guidelines suggests that the use of RPA III class is not common sense in selection of patients for WBRT.

Fifth, we did not have data regarding neurological outcome or quality of life after WBRT. However, other studies found no additive value of WBRT in RPA class III patients/patients with adverse prognostic factors $[10,16,23]$. Considering the results in our study and bearing in mind the poor outcome of RPA class III patients, the use of RPA class for selection of lung cancer patients for WBRT should be stressed. At the moment the latter is most precisely described in the Dutch guideline, but in our opinion other guidelines should also stress the importance of selecting the right patients. To facilitate this, a prognostic classification and not only performance status should be implemented in other guidelines. Physicians should be aware of their overestimation of the effect of WBRT on quality of life for the patient or even survival. Discussing disease prognosis, the effects and the side effects of WBRT with patients having brain metastases by their referring physicians is important. These patients should also be discussed in multidisciplinary meetings.

\section{Conclusion}

Although the Dutch guideline does not advise WBRT in RPA class III patients, $14.9-16.2 \%$ of the studied 
WBRT patients were class RPA III. Despite the release/implementation of the new multidisciplinary national guideline in 2011, no decrease in referral of RPA class III patients for WBRT was observed. Reasons for referral despite a low performance score were not found. The survival of RPA class III patients is poor and in agreement with the RTOG validation studies. In our view, guidelines should be implemented more precisely and a prognostic classification should also be implemented in other guidelines. Better awareness amongst physicians and correct information of patients on treatment expectations would prevent some patients from being treated unnecessarily.

Declaration of interest: The authors report no conflicts of interest. The authors alone are responsible for the content and writing of the paper.

\section{References}

[1] Gavrilovic IT, Posner JB. Brain metastases: Epidemiology and pathophysiology. J Neurooncol 2005;75:5-14.

[2] Lagerwaard FJ, Levendag PC, Nowak PJ, Eijkenboom WM, Hanssens PE, Schmitz PI. Identification of prognostic factors in patients with brain metastases: A review of 1292 patients. Int J Radiat Oncol Biol Phys 1999;43:795-803.

[3] Ceresoli GL, Reni M, Chiesa G, Carretta A, Schipani S, Passoni $\mathrm{P}$, et al. Brain metastases in locally advanced nonsmall cell lung carcinoma after multimodality treatment: Risk factors analysis. Cancer 2002;95:605-12.

[4] Quan AL, Videtic GM, Suh JH. Brain metastases in small cell lung cancer. Oncology (Williston Park) 2004;18:961-72; discussion 74, 79-80, 87.

[5] Gaspar L, Scott C, Rotman M, Asbell S, Phillips T, Wasserman $T$, et al. Recursive partitioning analysis (RPA) of prognostic factors in three Radiation Therapy Oncology Group (RTOG) brain metastases trials. Int J Radiat Oncol Biol Phys 1997;37:745-51.

[6] Kepka L, Cieslak E, Bujko K, Fijuth J, Wierzchowski M. Results of the whole-brain radiotherapy for patients with brain metastases from lung cancer: The RTOG RPA intraclasses analysis. Acta Oncol 2005;44:389-98.

[7] Videtic GM, Adelstein DJ, Mekhail TM, Rice TW, Stevens GH, Lee SY, et al. Validation of the RTOG recursive partitioning analysis (RPA) classification for small-cell lung cancer-only brain metastases. Int J Radiat Oncol Biol Phys 2007;67:240-3.

[8] Chu FC, Hilaris BB. Value of radiation theray in the management of intracranial metastases. Cancer 1961;14:577-81.

[9] Tsao MN, Lloyd N, Wong R, Chow E, Rakovitch E, Laperriere $\mathrm{N}$. Whole brain radiotherapy for the treatment of multiple brain metastases. Cochrane Database Syst Rev 2006;(3):CD003869.

[10] Langley RE, Stephens RJ, Nankivell M, Pugh C, Moore B, Navani N, et al. Interim data from the Medical Research Council QUARTZ Trial: Does whole brain radiotherapy affect the survival and quality of life of patients with brain metastases from non-small cell lung cancer? Clin Oncol 2013;25:e23-30.

[11] NICE clinical guideline 121: The diagnosis and treatment of lung cancer. 2011:103-4.

[12] NCCN guidelines: Central nervous system cancers. version 2.2012. 2012:MS-25.

[13] Peters S, Adjei AA, Gridelli C, Reck M, Kerr K, Felip E, et al. Metastatic non-small-cell lung cancer (NSCLC): ESMO Clinical Practice Guidelines for diagnosis, treatment and follow-up. Ann Oncol 2012;23(Suppl 7):vii56-64.

[14] LWNO/ IKL richtlijn: "hersenmetastasen van solide tumoren". 2011:17-22.

[15] Zindler JD, Rodrigues G, Haasbeek CJ, De Haan PF, Meijer OW, Slotman BJ, et al. The clinical utility of prognostic scoring systems in patients with brain metastases treated with radiosurgery. Radiother Oncol 2013;106:370-4.

[16] Nieder C, Norum J, Dalhaug A, Aandahl G, Pawinski A. Radiotherapy versus best supportive care in patients with brain metastases and adverse prognostic factors. Clin Exp Metastasis 2013;30:723-9.

[17] Barnes EA, Chow E, Tsao MN, Bradley NM, Doyle M, $\mathrm{Li} \mathrm{K}$, et al. Physician expectations of treatment outcomes for patients with brain metastases referred for whole brain radiotherapy. Int J Radiat Oncol Biol Phys 2010;76:187-92.

[18] Extermann $M$, Albrand G, Chen H, Zanetta S, Schonwetter R, Zulian GB, et al. Are older French patients as willing as older American patients to undertake chemotherapy? J Clin Oncol 2003;21:3214-9.

[19] Cairncross JG, Kim JH, Posner JB. Radiation therapy for brain metastases. Ann Neurol 1980;7:529-41.

[20] Bezjak A, Adam J, Barton R, Panzarella T, Laperriere N, Wong CS, et al. Symptom response after palliative radiotherapy for patients with brain metastases. Eur J Cancer 2002;38:487-96.

[21] Tsao MN, Lloyd N, Wong RK, Chow E, Rakovitch E, Laperriere $\mathrm{N}$, et al. Whole brain radiotherapy for the treatment of newly diagnosed multiple brain metastases. Cochrane Database Syst Rev 2012;4:CD003869.

[22] Wong J, Hird A, Zhang L, Tsao M, Sinclair E, Barnes E, et al. Symptoms and quality of life in cancer patients with brain metastases following palliative radiotherapy. Int J Radiat Oncol Biol Phys 2009;75:1125-31.

[23] Komosinska K, Kepka L, Niwinska A, Pietrzak L, Wierzchowski M, Tyc-Szczepaniak D, et al. Prospective evaluation of the palliative effect of whole-brain radiotherapy in patients with brain metastases and poor performance status. Acta Oncol 2010;49:382-8.

[24] Rodrigus P, de Brouwer P, Raaymakers E. Brain metastases and non-small cell lung cancer. Prognostic factors and correlation with survival after irradiation. Lung Cancer 2001; 32:129-36. 